\title{
Soil simulant sourcing for the ExoMars rover testbed
}

\author{
Thibault P. Gouache ${ }^{\mathrm{a}, \mathrm{b}, *}$, Nildeep Patel ${ }^{\mathrm{c}}$, Christopher Brunskill ${ }^{\mathrm{a}}$, Gregory P. Scott ${ }^{\mathrm{d}}$, Mini Saaj ${ }^{\mathrm{a}}$, Marcus Matthews ${ }^{\mathrm{e}}$, Liang Cui \\ ${ }^{a}$ University of Surrey, Surrey Space Centre, Guildford, GU2 7XH, United-Kingdom \\ ${ }^{b}$ University of Toulouse, Institute Clément Ader, ISAE/DMSM, Toulouse, 31055, France \\ ${ }^{c}$ EADS Astrium (UK) Ltd, Gunnels Wood Road, Stevenage, HERTS SG1 2AS, United-Kingdom \\ ${ }^{d}$ AstroTechnic Solutions, Springfield VA, 22152, USA \\ ${ }^{e}$ University of Surrey, Civil Engineering, Guildford, GU2 7XH, United-Kingdom
}

\begin{abstract}
ExoMars is the European Space Agency (ESA) mission to Mars planned for launch in 2018, focusing on exobiology with the primary objective of searching for any traces of extant or extinct carbon-based micro-organisms. The on-surface mission is performed by a near-autonomous mobile robotic vehicle (also referred to as the rover) with a mission design life of 180 sols Patel et al. (2010). In order to obtain useful data on the tractive performance of the ExoMars rover before flight, it is necessary to perform mobility tests on representative soil simulant materials producing a Martian terrain analogue under terrestrial laboratory conditions. Three individual types of regolith shown to be found extensively on the Martian surface were identified for replication using commercially available terrestrial materials Patel (2011), sourced from UK sites in order to ensure easy supply and reduce lead times for delivery. These materials (also referred to as the Engineering Soil Simulants (ES-x) are: a fine dust analogue (ES-1); a fine aeolian sand analogue (ES-2); and a coarse sand analogue (ES-3). Following a detailed analysis, three fine sand regolith types were identified from commercially available products. Each material was used in its off-the-shelf state, except for ES-2, where further processing methods were used to reduce the particle size range. These materials were tested to determine their physical characteristics, including the particle size distribution, dry bulk density, particle shape (including angularity / sphericity) and moisture content. The results are analysed to allow comparative analysis with existing soil simulants and the published results regarding in-situ analysis of Martian soil on previous NASA missions. The findings have shown that in some cases material properties vary significantly from the specifications provided by material suppliers. It has confirmed that laboratory testing is necessary to determine the actual parameters and that standard geotechnical processes are suitable for doing so. The outcomes have allowed the confirmation of each simulant material as suitable for replicating their respective regolith types.
\end{abstract}

Keywords: Mars, rover, ExoMars, terrain, regolith, soil, simulant, characterisation

\section{Introduction}

- The development of the mobility system of the ExoMars planetary exploration rover has been an extensive process of iterative analysis and testing. The baseline configuration is now confirmed as a 3-bogie suspension system, mechanically simpler than the dual rocker-bogie systems used on NASA Martian rovers while remaining equally capable on difficult terrains $\mathrm{Pa}$ tel et al. (2009). ExoMars will pioneer a unique new flexible wheel, designed to improve traction through increased contact area over an equivalent rigid wheel Patel et al. (2010). Wheel concepts from both ExoMars and the MERs are shown in Fig. 1. Much of the assessment of these systems has relied heavily on analytical modelling of the mechanical performance of the chassis during traverses across typical Mars-type terrains, replicating the slopes and rock distributions observed on previous Mars missions. Some experimental work has provided empirical data supporting these results, and the flexible wheel development has also included traction testing across loose, sandy

\footnotetext{
${ }^{*}$ Corresponding author

Email address: thibault.gouache@isae.fr; t.gouache@surrey.ac.uk (Thibault P. Gouache)
}

terrain similar to the regolith found on the Martian slopes (sand dunes). The final validation stages for the mobility system will rely on the combination of these methods, and require a thorough testing of a full, terrestrial prototype of the rover on laboratory terrain analogues. This will include the use of Engineering Soil Simulants that have been selected due to their mechanical similarities to those the ExoMars rover is likely to encounter when traversing the Martian regolith.

The use of regolith simulants in terrestrial laboratories is common practice Oravec et al. (2010). These materials allow for terrains extremely similar to those found on planetary surfaces to be prepared. Thanks to the numerous lander and rover missions sent to explore the Martian surface, some data are available on the material composition of soil at various sites across the planet. Two of the earliest Martian missions, the Viking I and II landers, searched for evidence of life and water with a robotic scoop, used to scrape away at the top few centimetres of the regolith surrounding the landing sites. In the 1990s the Pathfinder lander touched down on Mars carrying the Sojourner microrover, subsequently proving traversal of the Martian regolith as possible. Sojourner also carried the Wheel 


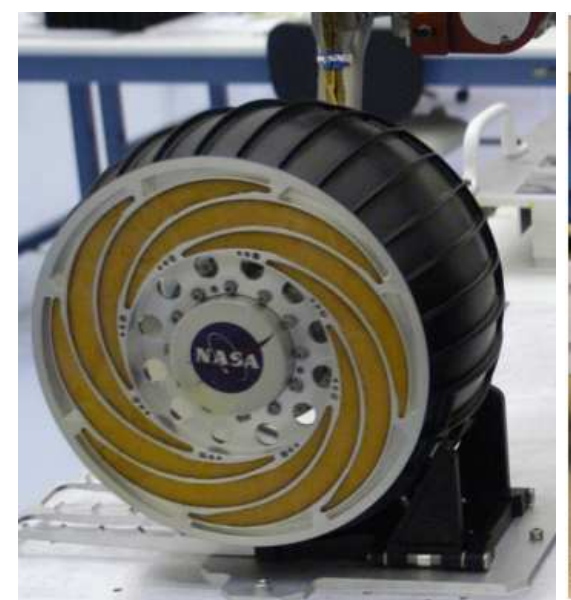

(a) MER wheel.

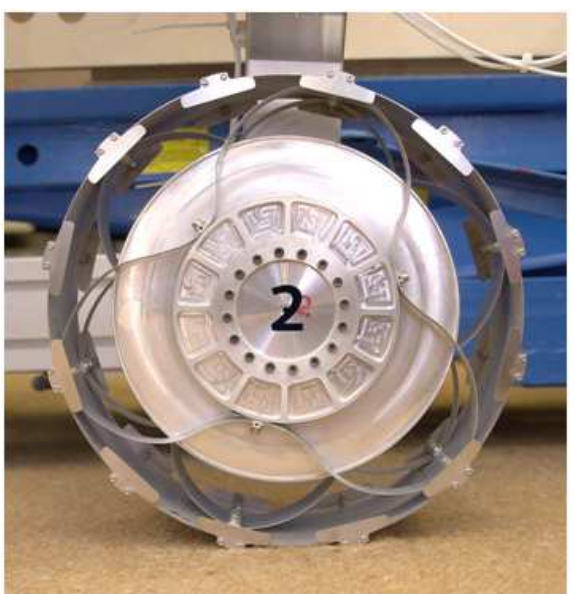

(b) ExoMars flexible wheel, Patel et al. (2010).

Figure 1: Examples of planetary rover wheels.

Abrasion Experiment (WAE) and used it successfully to profile the abrasiveness of the regolith particulates, in turn providing insight into the particle shapes. The two Mars Exploration Rover (MER) missions following Pathfinder carried the first optical microscopes to Mars, in addition to several spectrometers, and thanks to the unprecedented success of these rovers we now have regolith composition data from a huge range of sites across many kilometres Herkenhoff et al. (2008). The latest lander mission to Mars, Phoenix, extended the findings from the Viking missions. The primary experiment carried on the lander, the Thermal and Evolved Gas Analyser (TEGA), further profiled the compounds found in the regolith and the trenches left by the scoop action provided some indication of the mechanical behaviour to terrain analysts Bonitz et al. (2008).

. The challenge for engineers is to ensure the terrestrial materials used in these cases are similar in their physical and mechanical parameters to those observed on the Martian surface. Common mechanical parameters, such as the internal friction angle and cohesion, are often used as a specification. However, other physical parameters, including particle size distribution, dry bulk density and particle shape (including grain angularity/sphericity), must also be considered. For the purpose of traction testing, the chemical composition of prospective simulant materials is not normally necessary for consideration during the selection process; Seiferlin et al. (2008). The mechanical parameters of the following Engineering Soil Simulants are discussed in Brunskill et al. (Submitted). Three material types were identified for use in ExoMars traction testing:

- Engineering Soil Simulant-1 (ES-1): a fine dust analogue

- Engineering Soil Simulant-2 (ES-2): a fine aeolian sand analogue

- Engineering Soil Simulant-3 (ES-3): a coarse sand analogue
. These materials represent respectively the material comprising the fine covering found across the Martian surface, the aeolian materials commonly found in larger accumulations such as dunes, and coarser materials also found on these slopes. Fig. 2 provides an image indicating the MER Spirit in an attempt to traverse similar materials on the Martian surface. This terrain type has resulted in the rover becoming trapped in the loose regolith. A more thorough review of these Martian sand types is provided in Golombek et al. (2008). The simulant material selected in each case was chosen based on the modal particle size distribution.

. This paper will detail the processes and reasoning used to make these selections. Firstly the physical and mechanical parameters used in the selection will be defined, and a brief summary of other simulants currently in use will be presented. The options considered for the simulants are discussed and reasoning provided for the materials selected. The test methodology used to analyse each of the selected materials will be explained and results presented. Finally the measured parameters are compared with the required specification and the specification found in the respective data sheets.

\section{Defining simulant properties}

- Analysis of the Martian terrain and topography has formed a major part of almost every orbiter, lander and rover mission to the planet. Characterisation of the composition of the Martian surface is crucial for future mission development, whether in determining the functionality of new instruments and experiments or, more practically, in the design of lander and rover hardware for use on the extreme conditions presented by the terrain types.

\subsection{Simulant parameters}

- The parameters used to define a simulant are the same as those used in the study of the physical and mechanical properties of granular soils for geotechnical purposes. These are both 


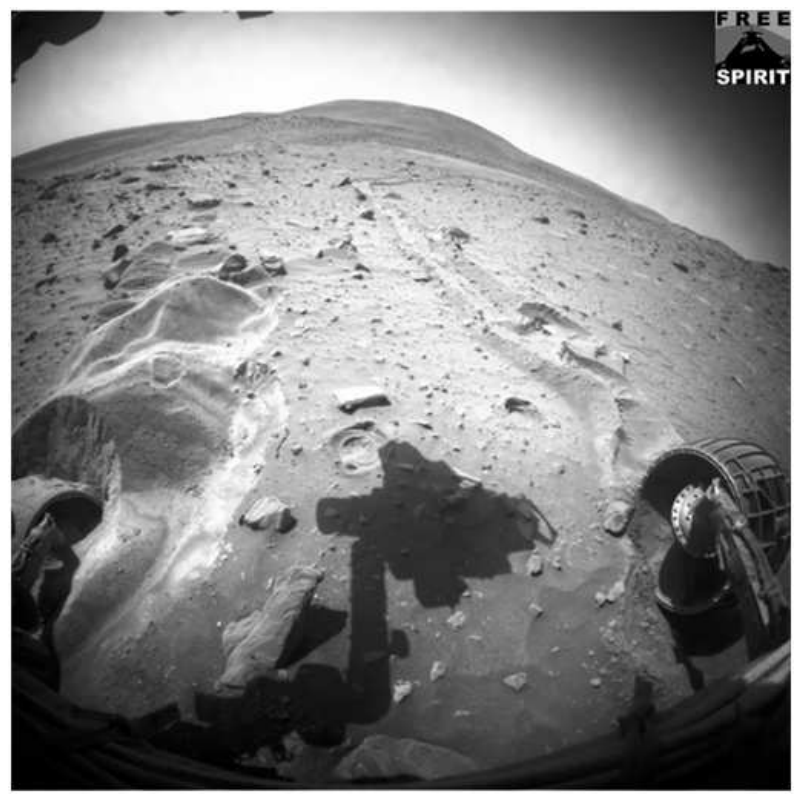

Figure 2: Loose regolith on the Martian terrain (Courtesy NASA/JPL-Caltech).

quantitative and qualitative in nature, providing a complete description of the physical and mechanical properties from the individual particle to the soil mass. It is these parameters which are used in the modelling of soil strength and prediction of trafficability for vehicle applications. It is also understood that in many cases these parameters are highly empirical. Testing is carried out on selected samples of the chosen simulant material; however, it is rare to find loose materials in wide-spread homogenous regions. Subtle differences in the grading mix, moisture content and shape can significantly alter measured properties. As such it is normally necessary to take multiple measurements and provide either an average value or parameter range for a specific terrain region.

. The materials discussed in this paper are distinguished. The three material types identified for this investigation are classified primarily by their particle size distribution. Additional physical properties also identified in the classification process include particle density and particle shape. Measuring particle density will allow to determine the void ratio of the different simulants when prepared at different bulk densities thanks to various preparation methods Gouache et al. (2010). The testing of the mechanical parameters, discussed in full in Brunskill et al. (Submitted), require the density of each sample to be varied. To provide a value of the relative density, maximum and minimum density measurements are required. Particle shape provides evidence useful in the analysis of the shear strength properties of each material.

\subsection{Martian terrain types}

- Mars is a dry planet with surface temperatures well below the freezing point of water. There are no known major bodies of surface water, leaving the terrain barren and similar to hot deserts on Earth. Conditions are analogous to several locations on the Earth's surface; the dryness and deep, loose sand of the hot deserts, rocky outcrops and plateaux of volcanic lava rock fields. Indeed, many topographical and terrain analogues can also be found in numerous regions in Australia, including rocky plains similar to those observed by the Viking 1 lander West et al. (2010), and the similarities of many regions of Argentina to the Martian surface are discussed in Pacifici (2009). These include large scale formations, tabular lava flows and meteorite impact-like craters, to much more localised examples, such as rocky till deposits in smaller sloped regions similar to that shown in Fig. 3.

- On a far smaller scale, the discussion in Golombek et al. (2008) identifies numerous soil types on the Martian surface, including aeolian deposits, based on Viking, Pathfinder/Sojourner and MER data. These include drift deposits, having low friction angles in the region of 15-21 degrees and low bulk densities of $1.0-1.3 \mathrm{~g} / \mathrm{cc}$. These are likely to be atmospheric dust particles, 2-4 $\mu \mathrm{m}$ in diameter, yet found in deposits thick enough to envelope an entire footpad of Viking 1, a sinkage of $16.5 \mathrm{~cm}$. The terrain surroundings of the MER rovers have also been analysed using the Mini-TES and Microscope Imager (MI) instruments on both Spirit and Opportunity. Measurements of fine grained dust have indicated particle sizes of up to $45 \mu \mathrm{m}$. When observing less fine sand deposits comprising the dunes and bedforms, Opportunity has found them to be relatively dust free, with particle sizes of approximately $130-160 \mu \mathrm{m}$. Spirit has also observed similar sand bedforms with particle sizes of approximately $60-160 \mu \mathrm{m}$.

- These measurements made by the various Martian surface missions can be used to select (or create) terrestrial materials 

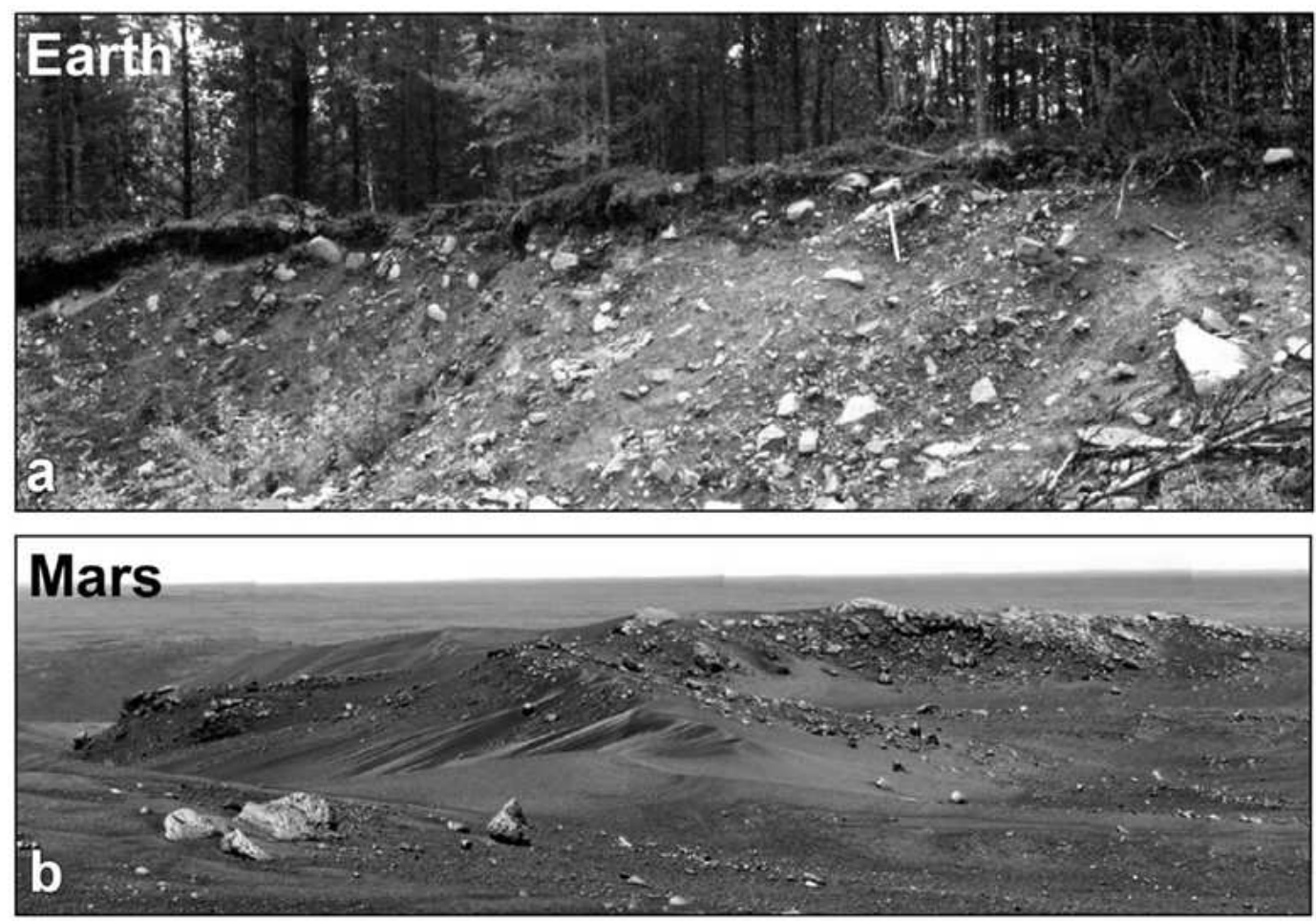

Figure 3: Martian and terrestrial scree slopes, Pacifici (2009).

analogous in their behaviour, dependent on the required application. In the case of materials replicating the trafficability properties of particular terrain, a broad and mature set of geotechnical test methods and standards can be used to ensure appropriate materials are selected. The materials in question will need to be close in mechanical nature to those anticipated at a particular mission site. Factors such as the chemical composition need not be considered in these cases. Furthermore the terms "soil", "regolith" and "simulant" are used interchangeably throughout this paper. Although strictly speaking the term "soil" can in some cases imply the presence of biological processes in its development Seiferlin et al. (2008), this should not be assumed to be the case here. Additionally, "regolith" is commonly used to describe loose materials comprising of a broad range of particle grain sizes and larger objects such as gravel, rocks and boulders Heiken et al. (1991). The materials used here are all assumed to be homogenous in their particle size distributions.

\subsection{Simulants in use today}

. The source material used in the manufacture of a simulant is dependent on the desired application of the final product. Other than physical and mechanical simulation, analogues may be selected to replicate properties including the chemical, magnetic, thermal or organic behaviour Marlow et al. (2008). Mechanical soil simulants for Martian testing have been primarily sourced by NASA JPL from two locations, the Hawaiian volcanic regions and the Mojave Desert. The weathered ash deposits of Hawaiian volcanoes were used to manufacture the simulant JSC Mars-1 throughout the 1990s. However, in more recent years the Pathfinder, Mars Exploration Rover (MER) and Phoenix missions have provided data on a broad range of areas from widespread Martian surface locations Peters et al. (2008). These data informed the development of a follow up simulant with mechanical parameters closer to those measurements, the Mojave Mars Simulant (MMS). Other simulants are in use in the various laboratories situated at JPL. These include crushed volcanic rock, used in the MER yard; a decomposed granite and brick dust mixture, used in the more general purpose Mars Yard; a dust free and washed silica sand in the JPL Lab 107; finally a dust free garnet mix is used in JPL Lab 82 Perko et al. (2006). ExoMars rover traction testing, until recently, has been performed on various dust-free washed and dry quartz sand in the Astrium Mars Yard Patel et al. (2009). Martian soil simulants in use at the Surrey Space Centre are also produced from similar source materials. SSC-1 is a coarse, dusty silica sand and SSC-2 a crushed garnet powder Brunskill and Lappas (2009); Scott and Saaj (2009).

. It is seen that material simulants can be sourced widely from carefully selected sites across the Earth's surface. The data provided by the Viking, Pathfinder, MER and Phoenix missions have extensively characterised and classified the most broadly encountered regolith types. These results provide all the information necessary to select new materials from local sources for specific terrain simulation requirements, regardless of the geographic location of the laboratory. 


\section{Material selection}

The materials considered below are all commercially available products, procurable "off the shelf" in large bulk quantities. The final products selected for the new simulants were initially purchased in smaller quantities of 1-2 tonnes, however, the outcome of the testing regime discussed below was intended to confirm the physical and mechanical parameters were within the required specification. On completion of a successful test campaign, the specification called for the selected materials to be available in bulk quantities in excess of 70 tonnes within a period of few days. This ruled out the option of sourcing the simulants from new, raw materials to reduce both the time required for production and the final cost of procurement.

\subsection{Required specification}

In an Astrium-led study on common Martian regolith types, silica sands and Nepheline powder were identified as ideal base substances for ES-2, ES-3; and ES-1 respectively Patel (2011). These materials shared many of the properties observed in the various regolith types found on the Martian surface, specifically in the particle size distributions and particle densities. Potential materials were selected from commercially available products based on the particle size distribution (PSD) ranges specified in Table 1. Numerous materials were investigated to fulfil this specification, the PSD data from the specification sheets of a selection of these potential products are shown in Fig. 4.

Table 1: Particle size distribution requirements.

\subsection{Post-processing silica sand materials}

Two different post-processing methods were used in an attempt to remove the oversize material from the Red Hill 110 sand, industrial scale sieving and milling. Large wire mesh sieves are fed with the desired material and vibrated to agitate the particles down the length of the sieve. As the material passes over the sieve particles fitting or below the mesh grade are removed and collected, leaving the excess to accumulate at the end of the process. This method is moderately fast, but does require extensive set up of the machinery, which may add several days to the overall processing time. With respect to this, it is normal for bulk quantities to be measured in tens of tonnes, to improve the overall efficiency of a processing run.

The alternative approach made use of a milling process to reduce the larger particles to sizes within the required specification, rather than removing them outright. Material is ground between two plates for a time proportional to the average needed in breaking down the portion of larger particles. An air classification system is then used to remove any excess in the fines produced in this method. The processing quantities and equipment reset times were similar to those of the sieving method. In both cases a relatively small quantity of 3 tonnes of Red Hill 110 was provided, used as a test sample to assess the effectiveness of the machinery in achieving an output close to the ES-2 specification. The quantity was determined by the requirement of 1 tonne of ES-2 to complete the mechanical testing from the expected best case yield (using the sieving process) of $40 \%$.

\begin{tabular}{lccc}
\hline \hline Soil & Modal size $(\mu \mathrm{m})$ & Maximum size $(\mu \mathrm{m})$ & Minimum size \\
\hline ES-1 & 10 & 32 & $<10$ \\
ES-2 & - & 125 & $>30$ \\
ES-3 & $400-600$ & 20,000 & $>30$ \\
\hline \hline
\end{tabular}

Despite promising initial results in tests of small samples of Red Hill 110 using hand sieves, the bulk sieving equipment struggled to maintain high yields of output material, typically $10 \%$ or worse. Further investigation showed the vibration method used did not prevent the sieves from becoming excessively clogged, or pegged, by larger particles. A sample was tested using a mechanical laboratory vibration platform at the University of Surrey and verified the problem. Fig. 5(a) shows the datasheet grading data of Red Hill 110. It also shows the PSD plots for a single sample of Red Hill 110 run through the mechanical vibration platform multiple times; the contents of the sieves left untouched with each run, except for the $150 \mu \mathrm{m}$ contents which were passed back through the stack. This confirmed the pegging issue identified by the processing company. It was suggested the most likely cause for the unexpectedly high levels of pegging was due to the original target size of the particles. In the case of Red Hill 110 it is likely this was close to or at the $125 \mu \mathrm{m}$ upper limit set in the ES-2 specification. The action of crushing and milling larger gravel and rock pieces produces a wide range of particle sizes; however, the process aims for a target modal particle size. This is likely to have been equal or close to the targeted upper limit of $125 \mu \mathrm{m}$ and resulting in the high pegging rate encountered during processing. This outcome resulted in the investigation of alternative processing methods.

Further milling of the material would remove the larger particles through a crushing process. Two tonnes of Red Hill 110 was subjected to the milling process and the resulting material 


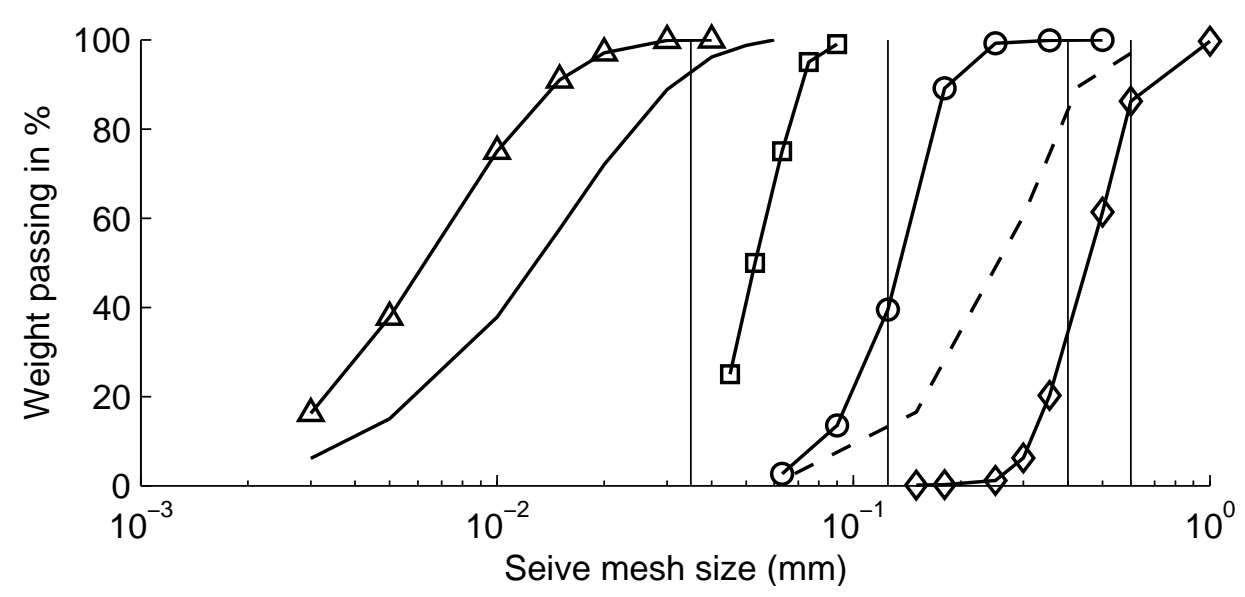

Figure 4: Materials initially proposed for use. The vertical black lines show the particle size range requirements. The different materials are represetned by: triangles (Stejorny 7), full line (Stejorny 4), squares (SSC-2), circles (Red Hill 110), dotted line (SSC-1) and diamonds (Leighton Buzard).

was found to be free from oversize particles. However, the particle strength was found to be much lower than that of similar materials. A yield of approximately $50 \%$ was estimated from this process. However, on examination of the milled Red Hill 110 approximately $75 \%$ fell outside of the lower particle size boundary. A PSD plot is shown in Fig. 5(b). Even when air classified the remaining material would retain a high bias in PSD toward the much finer material and the overall yield from the entire process would still fall slightly below the quantity required for mechanical parameter testing. Furthermore, the process of milling can tend to produce highly angular particles, where aeolian sands are typically well rounded. This was not acceptable in the final material which would make up ES-2.

\subsection{Final simulant materials}

. The material selected and procured for ES-1 was a dry Nepheline powder. Various options were available from the supplier and Stjernoy 7 was selected as the final material for use as the simulant (as noted above). Due to the problematic nature of the procurement and post-processing of a material for use as ES-2, no material was obtained in the large quantities needed to complete all mechanical testing. After an exhaustive search, off-the-shelf soils either fell outside of the particle size distribution requirements or were based on non-quartz mineral sands; neither of which were desired properties. The additional processing of Red Hill 110 proved unsuccessful in the attempts at manufacturing a suitable simulant in large quantities. In total, approximately $25 \mathrm{~kg}$ was produced as part of the sieving process out of the procured 2 tonnes and it is this material which is used as ES-2 in the following tests. The quartz-based Leighton Buzzard DA 30 sand, available off-the-shelf from Sibelco, was selected for ES-3.

\section{Simulant physical properties}

\subsection{Density}

- The particle density is measured using a graduated cylinder containing a known volume of water (by mass), based on the standard method in ASTM (2010). A known mass of dry simulant is added to the cylinder in a quantity small enough to allow the complete submersion of the sample. The change in total volume is measured and the volume of water subtracted. The resulting volume is that of the sample and is used with the mass to calculate the particle density. The results are presented in Table 2.

Table 2: Simulant specific gravities.

\begin{tabular}{lcc}
\hline \hline Simulant & Specific gravity (measured) & Specific gravity (nominal) \\
\hline ES-1 & 2.32 & $2.55-2.65$ (Nepheline) \\
ES-2 & 2.56 & $2.60-2.70$ (Quartz) \\
ES-3 & 2.60 & \\
\hline \hline
\end{tabular}

\subsection{Particle shape}

- An ideal simulant would match both the PSD and shape parameters identified in the specification. However, this laid too tight a constraint on the available materials to fulfil both parameters. For example, the crushing and milling used to obtain the targeted PSD for ES-2 generated angular to sub-angular particle shapes where subrounded particles were preferred. As such, particle shape was considered secondary to an appropriate PSD in the selection of the materials used for each simulant. It is, however, still of interest to note the resultant particle shapes for future reference.

- Each simulant was observed under a microscope at magnifications of up to 10x. The resulting images were captured with a digital camera and are shown in Fig. 6. Bulk samples are also shown in this Figure. A summary of the resultant particle shapes is given in Table 3. 


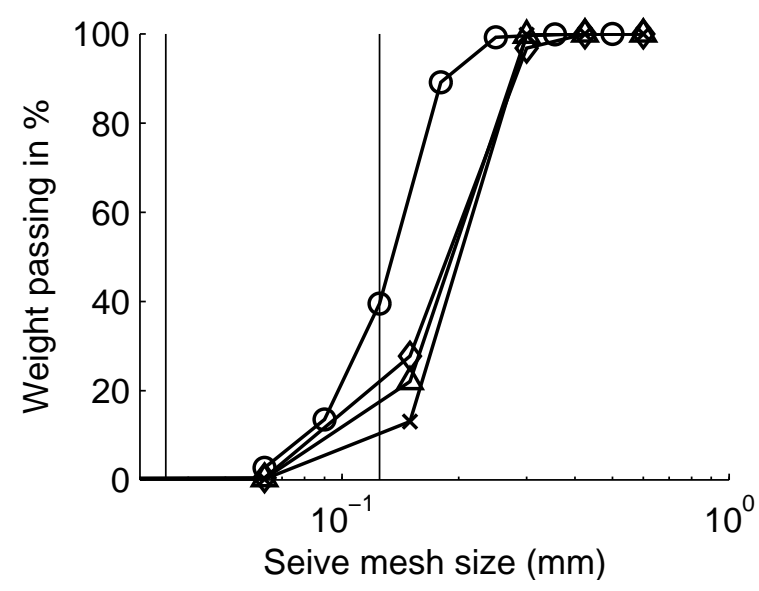

(a) The data is represented by: circles (Red hill 110 datasheet), crosses (Red hill 110 run 1), triangles (run 2) and diamonds (run 3).

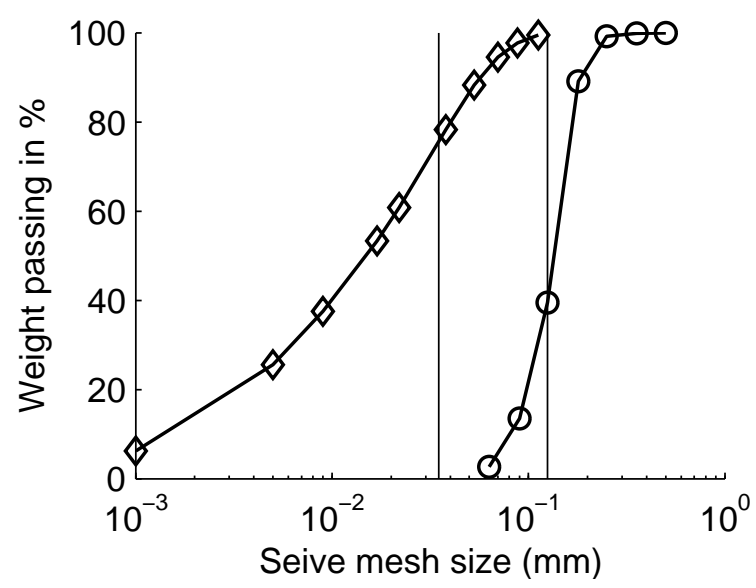

(b) The data is represented by: circles (Red hill 110 datasheet) and diamonds (milled Red hill 110).

Figure 5: (a) Variation in Red Hill 110 PSD with multiple sieving runs. (b) Comparison of PSD of milled Red Hill 110 and original Red Hill 110 . The vertical black lines show the particle size range requirements.

Table 3: Simulant particle shape analysis.

\begin{tabular}{lcc}
\hline \hline Simulant & Shape (observed) & Shape (specification) \\
\hline ES-1 & Angular & - \\
ES-2 & Angular to subangular & Subrounded \\
ES-3 & Subrounded to rounded & Angular to subangular \\
\hline \hline
\end{tabular}

\subsection{Particle size distribution}

. The PSD for each simulant was verified in the laboratory using samples of the final material. For these tests two methods were utilised:

Method 1: For the higher graded simulants (ES-2 and ES3) the ASTM D422-63(2002) ASTM (2002) standard was followed. As this standard is designed for particles of size greater than $75 \mu \mathrm{m}$, a minor modification to the standard was made by the addition of smaller mesh sieves, to determine the finer particle quantities. The sieving technique determines the percent weight passing a series of stacked sieves mounted to an Endecott type sieve shaker platform, providing lateral and longitudinal motion. Sieves were available at the following increments (all in $\mu \mathrm{m}$ ): 53, 63, 75, 90, 106, 125, 150, 212, 300, 425, 600, 850, and 1180 .

Method 2:. For the very fine simulant material used for ES-1 the ASTM standards do not apply. Therefore, an alternative method was employed, the Coulter Counter test. The fine particulate material is allowed to flow through a fluid and an electrical charge is passed through the particles to determine the size of the particles as they pass. This is used to determine the particle size distribution to sub-micron accuracy.
. Each simulant PSD was measured using the above methods to verify the data provided in the specification sheet. The PSD plots for all three simulants are shown in Fig. 7.

$E S-1$. The requirements for ES-1 stated that the upper range of the PSD be no greater than approximately $35 \mu \mathrm{m}$ and that the sample should also contain particles that are smaller than 10 $\mu \mathrm{m}$. The particles are, in general, slightly smaller than the technical specifications predicted. However, they meet the specification requirements generally.

ES-2. A sample of Red Hill 110 was acquired for PSD testing to confirm the range specified in the data sheet, as discussed in Section 3.2. The PSD plots shown in Fig. 5 are based on sieving tests run in the laboratory on Red Hill 110 and the grading data provided by the milling company after the alternative method was attempted. The data shows that the sieving process was ultimately effective at removing the upper portion of grades; however, the yield was severely limited by the sieve pegging issues.

ES-3. There were no difficulties in procuring this material. The material being simple, i.e. silica based sand, and available directly off-the-shelf with no additional processing required; it was accepted as the material for simulant ES-3 after confirming the PSD was appropriate. A small sample of the material was also subjected to the ASTM standard test method.

\subsection{Moisture content}

- Latent moisture is present in both the laboratory atmosphere and as a part of the simulant material. Atmospheric moisture was measured daily during the testing using a humidity monitor and maintained with the building climate control system and a dehumidifier, where necessary. Tests were carried out in "dry conditions", humidity levels between $25 \%$ and $40 \%$ in the case of these results. 

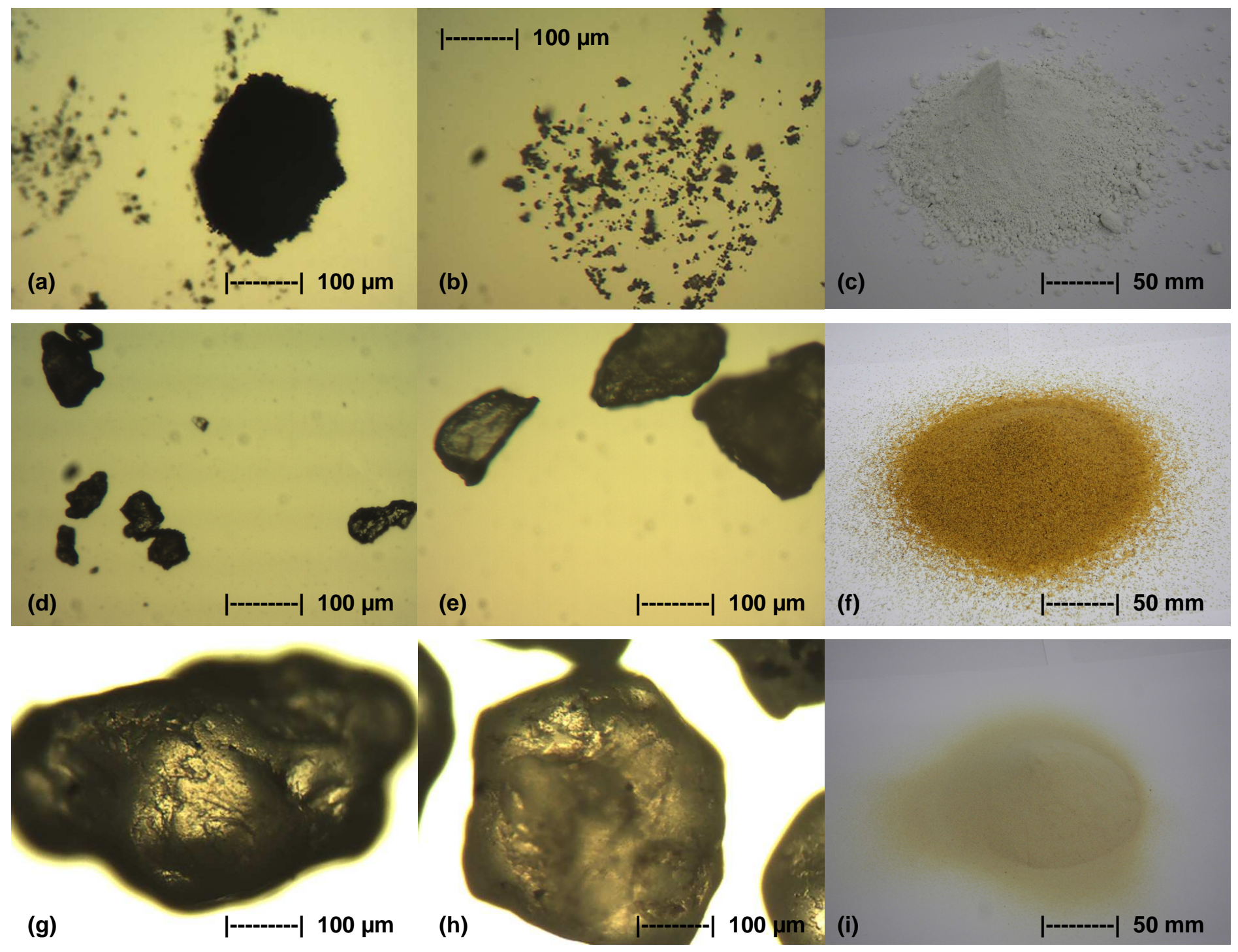

Figure 6: Microscope images of ES-1 (a, b), ES-2 (d, e) and ES-3 (g, h) and bulk samples of ES-1 (c), ES-2 (f) and ES-3 (i).

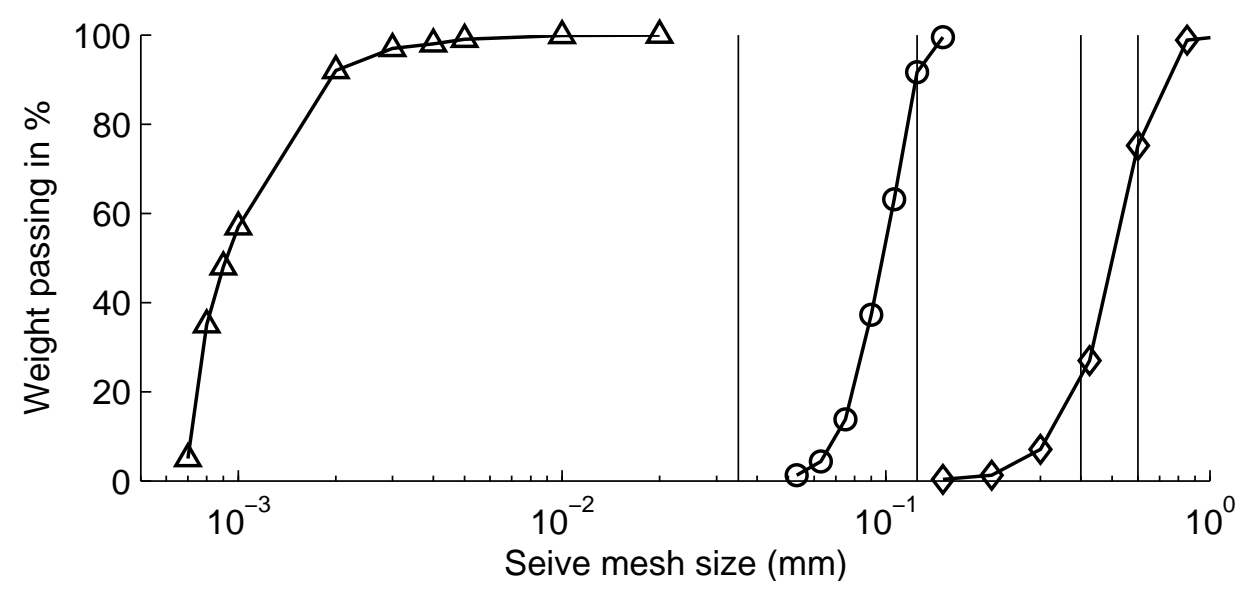

Figure 7: Particle size distribution plots for ES-1, ES-2 and ES-3 obtained experimentally. The data is represented by: triangles (ES-1), circles (ES-2) and diamonds (ES-3). The vertical black lines show the particle size range requirements. 
. The moisture content of each simulant was measured using a sample of the material used in each of the conducted tests; including those discussed in this paper and in the additional mechanical tests Brunskill et al. (Submitted). The method used followed the ASTM D2216-05 ASTM (2005) standard. To manage the moisture content variation through the duration of the testing regime, the soils were secured in air tight steel drums and stored in a dry laboratory space. Three samples of each of the three soils were collected under normal conditions, weighed, and dried in an oven at 120 for 48 hours (since no more mass variation was observed after $48 \mathrm{~h}$ ). The difference in mass was recorded to determine the moisture content as a percentage. The results are averaged to determine the overall moisture content of each simulant, shown in Table 4. Each simulant has a moisture content of significantly less than one percent. For the purposes of a Martian regolith simulant this is considered dry enough to provide an appropriate analogue of the mechanical behaviour.

\begin{tabular}{cc} 
Table 4: Moisture content of each simulant from test samples \\
\hline \hline Simulant & Average moisture content (\%) \\
\hline ES-1 & 0.35 \\
ES-2 & 0.20 \\
ES-3 & 0.34 \\
\hline \hline
\end{tabular}

\section{Discussion}

- The question of what makes a suitable regolith analogues would appear to be strongly influenced by the application intended for its use and the interpretation of data available in the quantification of the material properties. For the purpose of the study described here, three Martian soil simulants were selected based on the identification of distinct examples of drift sands. These loose, dry regions of a planetary surface present one of the most challenging terrains over which an autonomous rover is required to traverse. Variations in the surface compaction and structure can vary widely, instantly and unexpectedly. To understand the surface trafficability when considering the terramechanics of such robotic exploration vehicles, it is necessary to fully understand the parameters which describe the soil mechanics of the terrain in question.

. The described simulants for the testing of the ExoMars rover mobility performance were selected based on the particle size distribution. The ability in two of the three cases to procure materials off-the-shelf presented a quick, low-cost method to produce terrain analogues for vehicle testing. This approach provides considerable time, cost and human resource savings compared to those identified in other, similar simulants when manufacturing the material from a raw source, such as a rock bed. Moreover, the attempts to use post-processing methods produced unpredictable and time consuming setbacks, specifically when starting with a material already subjected to some level of processing.
. With this in mind, the test regime adopted for each of the materials selected for their respective simulants resulted in a comprehensive set of fundamental particle property data. These will form the basis of all further mechanical behaviour analysis during the testing schedule both on the mechanical behaviour and the response to supporting a $300 \mathrm{~kg}$ exploration rover like ExoMars. It is worth noting at this stage that further experimentation with the simulant ES-1, based on a nepheline powder, could be performed to further characterise this interesting material. In the tests it has been treated as a granular material, as is the case with ES-2 and ES-3. However, further insight may be gained into the behaviour from the perspective of a powder material. This will be addressed in future experiments, which will also include a study of the particle shape and features at a greater magnification than that provided by the optical microscope.

A final observation on the selection of these materials is a brief discussion on the published particle size distributions and those measured in laboratory tests. Fig. 8 extends the plots in Fig. 5a to include ES-1 and ES-3 and their respective source materials, Nepheline and Leighton Buzzard silica sand. The data provided for Leighton Buzzard DA 30 closely matches the specification, however, the similar but less coarse Red Hill 110, as discussed above, presented difficulties in sieving it to the ES2 specification. The cause for this is assumed to be related to the sieve mesh size used. The lack of difficulty with the Leighton Buzzard sand would appear to indicate that a prudent choice in sieve sizes may help avoid issues such as these in future attempts using similar methods.

The Nepheline powder also appears to differ significantly in its PSD when compared to the published data. Many different methods exist to measure the particle size distribution. In general these data are inferred from indirect measurements and the results are only as good as the correlation relationship used in specifying the PSD. The Coulter Counter method used to measure the Nepheline PSD provided a better distribution based on the requirements of the experiments discussed in this paper.

\section{Conclusions}

. The selection of appropriate materials for use as soil simulants requires extensive work in source identification and validation of specification datasheet. While the range of options in general is considerably broad, the restriction to specific particle size ranges limited the choice of suitable materials. Sub-ranges of particle sizes have been identified within off-the-shelf materials in the post-processing methods used on Red Hill 110, most likely due to standards in target particle cut sizes when the source rock is ground at the processing stage. However, both ES-1 and ES-3 materials were found off-the-shelf with a fit within the accepted particle size ranges. No problems were encountered during procurement, delivery or during the parameter validation. 


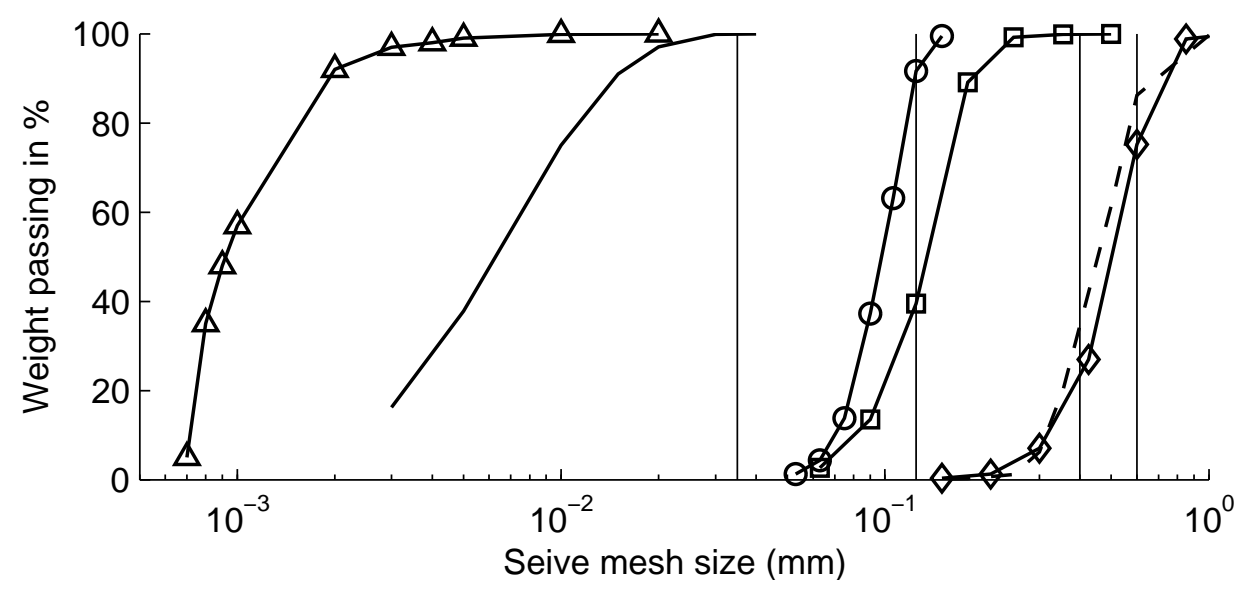

Figure 8: PSD comparison between datasheet values and measured values. The data is represented by: triangles (ES-1), circles (ES-2), diamonds (ES-3), full line (Nepheline), squares (Red Hill 110) and dashed line (Leighton Buzzard DA 30). The vertical black lines show the particle size range requirements.

. The tests performed on ES-1, ES-2 and ES-3 in the laboratory followed methods used widely in geotechnical engineering. The small sample of ES-2 matched the required distribution after processing, but was not available in large quantities. The Leighton Buzzard DA 30 used for ES-3 was the only offthe-shelf material to match its specification sheet. The Martian regolith simulants were selected primarily on their particle size distributions and modal particle size. However, with datasheets providing only guideline specifications and further problems highlighted when trying to validate the data using laboratory equipment (particularly when sieving), it has proved to be a particularly difficult parameter to work with.

. Future simulant specifications may benefit by the definition of a broader particle size distribution range and focus instead on ensuring suitable particle shapes. This also raises the underlying issue with the angular nature of the ES-2 simulant, as aeolian materials are commonly found to comprise of more rounded particles.

- From the perspective of mobility testing the materials selected for ES-1, ES-2 and ES-3 are considered suitable for use as simulants in the testing of the ExoMars rover. Although it is unlikely the Red Hill 110 on which ES-2 is based will be used extensively, due to the issues with bulk procurement, the wide availability and off-the-shelf suitability of Leighton Buzzard 30 and Nepheline syenite S7 showed them to be ideal matches for the analogue requirements.

\section{Acknowledgements}

- The work described in this paper was performed under a direct contract from EADS Astrium within the ESA ExoMars project for which Astrium is the prime contractor for the ExoMars rover vehicle and Thales Alenia - Italy is the ExoMars mission prime. The authors would like to thank the project teams involved with this study at Astrium, Thales and ESA.

ASTM, 2002. Standard test method for particle-size analysis of soils.
ASTM, 2005. Standard test methods for laboratory determination of water (moisture) content of soil and rock by mass.

ASTM, 2010. Standard test methods for specific gravity of soil solids by water pycnometer.

Bonitz, R., Shiraishi, L., Robinson, M., Arvidson, R., Chu, P., Wilson, J., Davis, K., Paulsen, G., Kusack, A., Archer, D., et al., 2008. NASA Mars 2007 Phoenix Lander Robotic Arm and Icy Soil Acquisition Device. J. Geophys. Res 113,--.

Brunskill, C., Lappas, V., 2009. The effect of relative soil density on microrover trafficability under low ground pressure conditions, in: Proceedings of the 2009 International Society for Terrain and Vehicle Systems (ISTVS) European Conference.

Brunskill, C., Patel, N., Gouache, T., Scott, G., Saaj, M., Matthews, M., Cui, L., Submitted. Martian soil simulant characterisation. Journal of Terramechanics

Golombek, M.P., Haldemann, A.F.C., Simpson, R.A., Fergason, R.L., Putzig, N.E., Arvidson, R.E., III, J.F.B., Mellon, M.T., 2008. Martian surface properties from joint analysis of orbital, Earth-based and surface observations. Cambridge University Press. chapter 21. pp. 468-497.

Gouache, T., Brunskill, C., Scott, G., Gourinat, Y., Coste, P., Gao, Y., 2010. Regolith simulant preparation methods for hardware testing. Planetary and Space Science .

Heiken, G., Vaniman, D., French, B., 1991. Lunar sourcebook: A user's guide to the Moon. Cambridge Univ Pr.

Herkenhoff, K.E., Golombek, M.P., Guinness, E.A., Johnson, J.B., Kusack, A., Richter, L., Sullivan, R.J., Gorevan, S., 2008. In situ observations of the physical properties of the Martian surface. Cambridge University Press. chapter 20. pp. 451-467.

Marlow, J., Martins, Z., Sephton, M., 2008. Mars on earth: soil analogues for future mars missions. Astronomy \& Geophysics 49, 2-20.

Oravec, H., Zeng, X., Asnani, V., 2010. Design and characterisation of grc-1: A soil for lunar terramechanics testing in earth-ambient conditions. Journal of Terramechanics 47, 361-377.

Pacifici, A., 2009. The Argentinean Patagonia and the Martian landscape. Planetary and Space Science 57, 571-578.

Patel, N., Slade, R., Clemmet, J., 2010. The exomars rover locomotion subsystem. Journal of Terramechanics 47, 227-242.

Patel, N., Slade, S., Clemmet, J., 2009. Traction performance trials of the exomars rover breadboards, in: 11th Regional Conference of the International Society for Terrain-Vehicle Systems (ISTVS).

Patel, N.e.a., 2011. Formulation of engineering soil simulants for the exomars mission. TBD TBD, TBD.

Perko, H., Nelson, J., Green, J., 2006. Mars soil mechanical properties and suitability of mars soil simulants. Journal of Aerospace Engineering 19, 169.

Peters, G., Abbey, W., Bearman, G., Mungas, G., Smith, J., Anderson, R., Douglas, S., Beegle, L., 2008. Mojave Mars simulant-Characterization of a 
new geologic Mars analog. Icarus 197, 470-479.

Scott, G., Saaj, C., 2009. Measuring and Simulating the Effect of Variations in Soil Properties on Microrover Trafficability.

Seiferlin, K., Ehrenfreund, P., Garry, J., Gunderson, K., H

"utter, E., Kargl, G., Maturilli, A., Merrison, J., 2008. Simulating martian regolith in the laboratory. Planetary and Space Science 56, 2009-2025.

West, M., Clarke, J., Thomas, M., Pain, C., Walter, M., 2010. The geology of Australian Mars analogue sites. Planetary and Space Science 58, 447-458. 